\title{
Keeping Them Home: Aboriginal Out-of-Home Care in Australia
}

\author{
Bruce Valentine \& Mel Gray
}

\begin{abstract}
This article examines the foster care ${ }^{1}$ (referred to as out-of-home care) of Aboriginal children ${ }^{2}$ in Australia. It discusses the Aboriginal Child Placement Principle (ACPP), the role of indigenous kinship care, ${ }^{3}$ and the self-determination of Aboriginal people. Given the history of Australia's stolen generations (generations of Aboriginal children who were forcibly removed from their families), the primary concern is to keep Aboriginal children at home within their families, communities, and culture. All Australian jurisdictions support the concept of Aboriginal self-determination and the ACPP. However, they do so from within a framework informed by non-Aboriginal values. As a consequence, Aboriginal people are frustrated about mainstream understanding of self-determination and the ACPP. The authors argue that for both of these objectives to be achieved culturally appropriate policies and practices are needed.
\end{abstract}

$\mathbf{T}$ he issue of Aboriginal out-of-home care is one fraught with difficulty given the divergent perspectives on the problems associated with Aboriginal child welfare and wide-ranging opinions on their cause and effect depending on one's point of view. This article focuses on a particular analysis of Aboriginal out-of-home care in Australia rather than on child welfare generally. Its purpose is to highlight the complexity of the issues involved and, more importantly, to articulate the Aboriginal perspective on these issues. It does so from both a theoretical and practice perspective as one of the authors (BV) has a practice background in outof-home care spanning 30 years, including working with Aboriginal families, communities, and organisations. From an Aboriginal perspective, the Australian legal system is unequal, racist, and culturally biased such that the present
Aboriginal care and protection system will not change until broader issues of Aboriginal trauma, dispossession, racism, and disadvantage are addressed.

While one might question whether the number of Aboriginal children in the care and protection system and in out-of-home care is related to these issues, it is nevertheless true that Aboriginal children are over-represented in the care system. As of June 30, 2004, the number of children aged 0 to 17 years in care Australia-wide was 21,795. Of this number, 5,059 or $23.2 \%$ of these children were Aboriginal, and 16,736 or $76.8 \%$ were non-Aboriginal. In considering the number of Aboriginal children whose placements conform to the Aboriginal Child Placement Principle (ACPP), data was only available for 2,553 Aboriginal children as figures for New South Wales (NSW) were not available. 
From the available data, 811 or $35.3 \%$ were in placements that did not conform to the ACPP (Australian Institute of Health and Welfare, 2005).

In NSW, the ACPP applies to all placements, i.e., both court-ordered and voluntary and both long- and shortterm. However, here, as in other states and territories, there are clearly difficulties in recruiting foster parents from within the Aboriginal community. There have been several attempts to address this situation; most recently, amendments were made to the NSW Children and Young Persons (Care and Protection) Act 1998 in 2001 to facilitate permanency planning. We discuss particular issues arising from such policy initiatives in relation to Aboriginal child care, contemporary research, and practice experience, and highlight the difficulties involved in balancing research data and practical considerations with cultural tensions.

Our title needs to be seen in light of the report produced by the Stolen Generations Commission in Australia entitled Bringing Them Home, the result of the National Inquiry into the Separation of Aboriginal and Torres Strait Islander Children from their Families undertaken by the Human Rights and Equal Opportunity Commission [HREOC] (1997). One of the purposes of this commission was to examine past laws, practices, and policies that resulted in the separation of Aboriginal and Torres Straight Islander children from their families. The report highlighted both past and present injustices and the underlying emotions felt by those taken away from their families. Some of those who testified continued to question "why we were taken away from our home. We were not neglected, we wore nice clothes, we were not starving; we came from a very close and loving family" (HREOC, 1997).

The inquiry also found that entrenched disadvantage and dispossession meant that the removal of indigenous children continues today: Indigenous children were six times more likely to be removed for child welfare reasons and 21 times more likely to be detained in a juvenile justice facility than non-indigenous children (HREOC, 1997). Among the report's recommendations was the development of national standards and legislation to ensure that children taken into care maintained contact with their indigenous family, community, and culture in recognition of the importance of their indigenous heritage for their future well-being.

Thus, the ultimate goal for indigenous children is to keep them home with their families and in the communities to which they belong. However, Aboriginal children continue to be placed with non-Aboriginal caregivers despite all Australian jurisdictions having implemented the ACPP, which was developed to counter this practice. According to the Australian Institute of Health and Welfare (2005), just over 23\% of children in care are Aboriginal with $35.3 \%$ of Aboriginal children in foster care placements that did not conform to the ACPP as the following discussion shows.

\section{The Aboriginal Child Placement Principle}

The inappropriate care provided to Aboriginal children has parallels with the historical treatment of First Nations peoples in the United States, Canada, and New Zealand and has similarities with legislative provisions in the previously mentioned countries (Sweeney, 1995). Developed in response to this inappropriate care, the intent of the ACPP is to provide a dynamic guide to the placement of Aboriginal children who are unable to remain with their parents, and to recognise the cultural context of Aboriginal child welfare practice and the right of Aboriginal people to receive culturally appropriate care and practice. Implicit in this principle is the desire to keep Aboriginal families together wherever possible and, where removal is unavoidable, to keep Aboriginal children with their extended families or communities. A social system that honors these principles and, by implication, protects the rights of Aboriginal people would ensure that policies and services supported practices consistent with these principles.

The ACPP seeks to do this by ensuring that priority is always given to the placement of Aboriginal children with a member of their extended family and failing this, placement within the Aboriginal community to which the child belongs or with another Aboriginal family as the next best option. It is only after exhausting all these options that placement with a non-Aboriginal family should be considered (Chisholm, 1988). While warmly welcomed as a way of making sure the first placement choice for an Aboriginal child is an Aboriginal family, ironically, when rigidly applied, it can also be a means of legitimating the placement of Aboriginal children with non-Aboriginal caregivers.

The ACPP was first mooted at a national adoption conference in 1976, formalised by the Federal Department of Aboriginal Affairs in 1980, and subsequently adopted by all jurisdictions in 1983. However, there was opposition to both the federal government legislating for the ACPP and the states undertaking to introduce uniform legislation. As a consequence, and to the disappointment of Aboriginal Child Welfare Agencies, it was left to each state to determine how best to implement the ACPP (Chisholm, 1988). However, over time the ACPP has become integral to all jurisdictions.

The intent of the ACPP is fourfold. First, it seeks to preserve each child's identity, heritage, and culture. Secondly, it recognizes that Aboriginal people should deliver from within their culture Aboriginal out-of-home care services. Thirdly, it locates and gives recognition to the historical construction of Aboriginal child welfare practices by implicitly acknowledging the past and present oppressive practices of non-Aboriginal culture. Finally, it recognizes the right of Aboriginal people to keep their culture and identity alive by passing them on to their children (Chisholm, 1988).

However, the ACPP is subject to a number of limitations. Most significantly, there is no requirement for 
Aboriginal children to be placed via an Aboriginal agency and many Aboriginal caregivers, for historical reasons, will not work with state agencies. In addition, even if an Aboriginal child is placed with an Aboriginal family by a non-Aboriginal agency, particularly if not supervised by an Aboriginal worker, Aboriginal culture is suppressed because the placement is subject to the dominant rules, mores, and conventions that inform non-Aboriginal policies, procedures, and practices as well as the values of nonAboriginal workers.

Secondly, as mentioned earlier, the ACPP can be used to legitimate the placement of Aboriginal children with non-Aboriginal caregivers. This can also occur when nonAboriginal workers discount Aboriginal care- givers as being unsuitable, often because the values of Aboriginal people do not accord with those of their culture. This is particularly so for
Central to this process [of culturally appropriate

programs] is the placement of Aboriginal

children through Aboriginal out-of-home care

agencies and the promotion of Aboriginal

foster care, referred to as indigenous kinship

care, with its emphasis upon identifying

significant relationships for Aboriginal children

in addition to those based on ties of blood and

marriage. government and Aboriginal agencies on how best to care port for Aboriginal agencies (Ah Kee \& Tilbury, 1999).

In summary, the ACPP should not be used to justify the placement of Aboriginal children with non-Aboriginal caregivers by nonAboriginal agencies. Rather the ACPP needs to both prevent the entry of Aboriginal children into nonAboriginal care situations and enable the transfer of Aboriginal children out of the care of non-Aboriginal culture to Aboriginal settings. There is a need to design and implement culturally appropriate policies and programs that are directed toward progressively increasing the number of Aboriginal children being placed with Aboriginal caregivers. Central to this process is the placement of Aboriginal children through Aboriginal short-term and emergency placements which, for various reasons, can become long-term arrangements. In this regard, the lack of Aboriginal caregivers, workers, and agencies is not considered sufficient justification to dismiss the ACPP as unworkable. Rather, these deficiencies are seen as the outcomes of a lack of planning, funding, and training of Aboriginal people by governments.

Thus the ACPP on its own has limited value. To be as effective as originally envisaged, it has to be part of a larger mosaic of strategies. These include funding, training, planning and cultural recognition to enable the development and delivery of a sufficient number of programs and services from within Aboriginal culture. If the ACPP is to be fully implemented, there is a need to develop planning and funding models in consultation with and as agreed to by each Aboriginal community (Ah Kee \& Tilbury, 1999).

In the meantime, Aboriginal children continue to be placed with non-Aboriginal caregivers and through nonAboriginal agencies (Ah Kee \& Tilbury, 1999). A further way in which the ACPP is bypassed is by non-Aboriginal workers ignoring or disputing the identity of Aboriginal children by challenging the heritage of a child based on their skin colour. There are also structural barriers between out-of-home care agencies and the promotion of Aboriginal foster care, referred to as indigenous kinship care, with its emphasis upon identifying significant relationships for Aboriginal children in addition to those based on ties of blood and marriage. This approach also requires that indigenous kinship care be seen as a form of care in its own right distinct from, rather than a subset of, foster care.

\section{The Value and Standing of Indigenous Kinship Care}

While in Australia the importance of Aboriginal children staying within their communities is recognized, other countries appear to be doing more to facilitate this. In the U.S., the Department of Health and Human Services (2006) provides a wide range of funding to enable Native Americans to provide culturally appropriate social and community services and employment programs and to promote self-government. The influential Child Welfare League of America $(2001,2003)$ has produced standards for kinship care and assessment. The American Bar Association (1999) also has approved assessment guide- 
lines for states to follow, including aggressive searches for kin and background checks.

In Canada, there is also recognition of the strong kinship ties of First Nations children with their communities and their culture. This has become an important issue in developing foster care standards for First Nations children in Canada (First Nations Child and Family Service [FNCFS], 2003a). Placing children with a member of their extended family, if appropriate, underlies the "best interests of the child" principle outlined in the standards (FNCFS, 2003, p.5). The FNCFS also highlights a variety of issues and practices that are of benefit to the child and the foster family and covers matters ranging from recruitment strategies to closure of the foster home. To complement this set of standards, all First Nation caregivers are given a copy of the Foster Family Care Manual (FNCFS, 2003b). This document covers most issues that may arise and be of concern to a foster family, therefore informing them of their rights and those of the child in their care. Further facilitating First Nations people being more self-determining, some of the provinces have delegated statutory responsibility for child protection and out-ofhome care services as well as financial delegations to the staff of First Nations agencies providing child welfare services.

The Maori child welfare system in Aotearoa, New Zealand also provides an interesting comparative insight into self-determining social development policies for Maori people. The Ministry of
Within Aboriginal society all state interventions, particularly those concerning children, are treated as being the same and are held to hold the same consequences - the risk of loss of their children to White society, the imposition of White values upon Aboriginal society, and the resultant suppression of Aboriginal culture and values.
Children, Young Persons and Their Families Act 1989 in the following principles:

Wherever possible, a child's or young person's family, whanau (extended family), hapu, iwi, and family group should participate in the making of decisions affecting that child or young person, and accordingly that, wherever possible, regard should be given to the views of that family, whanau, hapu, iwi, and family group.

Wherever possible, the relationship between a child or young person and his or her family, whanau, hapu, iwi, and family group should be maintained and strengthened.

Maori commentators similarly recognise the importance of Maori service providers delivering social services to Maori communities. Services that are delivered by Maori staff are based within Maori tikanga (protocols), beliefs, and practices, and this is important for whanau because it ensures that approaches are culturally safe for both workers and clients (Crengle, 1998).

In Australia, in the wake of the Bringing Them Home report (HREOC, 1997), while placing Aboriginal children with their kin and community has become a dominant out-ofhome care policy, it is not always reflected in practice. In addition, there continues to be debate in Australia, and internationally, on kinship care, specifically Social Development in Aotearoa outlines the government's approach to social development as "helping communities, hapu (sub tribe), and iwi (tribe) reach their potential by unlocking their unrealized resources, skills, and assets as a tool for achieving social development goals. The Ministry is working toward a New Zealand society where communities, hapu, and iwi are able to determine and achieve their vital and unique social, economic, and cultural goals" (Ministry of Social Development, 2006). This commitment to self-determination is also reflected in Section 5 of the New Zealand the legitimacy of kin as suitable caregivers for neglected and often traumatized children (Chipman, Wells, \& Johnson, 2002; Ehrle \& Geen, 2002; McHugh, 2003).

Leos-Urbel, Bess, and Geen (2002) argue that in the U.S., policy makers are grappling with how and when to treat kinship differently from traditional foster care placements. The evidence tends to suggest that kinship care, in practice, is treated as a lesser form of foster care, rather than as an identified form of care with specific requirements, standards, resource demands, and issues. Leos-Urbel et al. cite the Urban Institute Survey that 
assessed national kinship care policy and found a wide variation in state-based kinship care policies (Boots \& Geen, 1999). Some states require all kin to meet the same standards as non-kin foster parents; others have waived or modified some requirements for kin. With this variation in assessment standards, there is also variation in financial support given to kinship caregivers. They also raise important issues surrounding kinship care, such as children in state custody who are being cared for by kin having less likelihood of being reunited with their birth parents who, while having unlimited access to them, may forgo any responsibility toward them. In addition, kin may be hesitant to adopt a child because they are already related to them and may risk losing their foster care payments if they obtain legal custody, as the United States federal government does not reimburse states for ongoing payments made to guardians (Leos-Urbel et al., 2002).

Chipman et al. (2002) also express concern about the level of standards that exist in North American states in regard to kinship care, because they too found that standards vary widely from state to state. They found that most kinship caregivers are not licensed prior to a child being placed in their care. As a result, caseworkers often have little information on the caregiver at the time of placement, particularly in emergency situations. They also found that caseworkers might not have placed a child with a particular kinship caregiver if they had had more information. They further found that caseworkers did not believe that kin should be held to the same set of standards that non-kin have to abide by, but recognized the need to apply a minimum standard. They also found that a prior felony charge or a substantiated maltreatment report should not automatically disqualify relatives from serving as caregivers. For their part, caregivers reported that they needed more casework support in dealing with generational differences and the special needs of the children in their care.

McHugh (2003) argues that in Australia indigenous kinship care may be the better option for a variety of reasons, such as the child's shared biological, emotional, and cultural connections. Thus kinship care helps Aboriginal children maintain their cultural identity and connections, and this lessens the stigma of out-of-home care. However, as observed, while in theory kinship care seems to have more advantages than disadvantages, there are a number of significant issues to be addressed. In addition, in the short term at least, McHugh is concerned about the number of suitable Aboriginal foster parents that can be brought successfully into the system. At the moment, caregivers tend to be older females who are exploited and lack sufficient resources to look after vulnerable children adequately. Also, kin caregivers tend to be less likely to be expected to complete training, to have case plans, to be supervised, and to have support groups, or to have access to services (McHugh, 2003).
In addition, as Terling-Watt (2001) observes, in the U.S., there are a number of significant and unique features associated with kinship care. For instance, contact with parents can be more problematic for kinship caregivers; they can be uninformed and unrealistic about the challenges they will face and, at the same time, can be resistant to help and assistance. This all suggests that kinship care is significantly different from foster care and, while sharing some commonalities with foster care, it also has a significant number of unique issues. The fact that, in many instances, caregivers cannot be recruited in advance and the immediate need for a placement prevails over an adequate and considered assessment while family and community may have limited capacity to assist means that training and support services for kinship care have to reflect these factors. Given the nature of Aboriginal society, kinship care has to be a community activity and not limited to children and caregivers.

\section{Current Issues in Aboriginal Out-of-Home Care}

As an enduring issue and concern, the placement of a large number of Aboriginal children with nonAboriginal families needs further systematic research to explore why this continues to occur despite the aforementioned policies established to prevent this practice. The authors suggest that these strategies need to include the provision of additional resources to Aboriginal agencies offering out-of-home care services. Despite the fact that Aboriginal children represent $28 \%$ of children in care in New South Wales, for example, Aboriginal agencies receive only $11 \%$ of out-of-home care funding (New South Wales Department of Community Services, 2006 $\& 2004)$. There is a need to ensure that sufficient services exist in areas where there are large concentrations of Aboriginal people in the population and to establish services where none exist or where the demand exceeds the present capacity, such as Northern New South Wales. There is also a need to offer training and capacity-building for Aboriginal communities to enable them to care for their children.

Furthermore, these strategies should also involve culturally appropriate models of out-of-home care practice drawn from current research, including the substantial literature on child development, which reinforces the pivotal role of family and culture in the child's development and the growing literature on keeping siblings together as well as that on the importance of systems of kinship care (Groza et al., 2003). Central to the placing of Aboriginal children with Aboriginal caregivers is Aboriginal self-determination. Only Aboriginal communities can best care for Aboriginal children (Ah Kee \& Tilbury, 1999). However, there are a number of impediments to Aboriginal self-determination. 


\section{Barriers to Self-Determination}

Behrendt (2003), Stanley (2003), Mansell (2001), and Cunneen (1997) all highlight the difficulties faced by Aboriginal people in Australia as a result of their being located within a legal and structural framework that is imbued with inequalities, racism, and cultural tensions. Stanley (2003) points to the disparity between the reporting of non-Aboriginal child sexual assault (17\%) and Aboriginal child sexual assault (9\%) from 2001 through 2002. She attributes the under-reporting of child sexual assault by Aboriginal people to cultural differences and a lack of trust of the 'White' system. Many Aboriginal people believe that this situation will persist until the broader issues of Aboriginal trauma, dispossession, racism, and disadvantage are addressed.

Within Aboriginal society all state interventions, particularly those concerning children, are treated as being the same and are held to hold the same consequences- the risk of loss of their children to White society, the imposition of White values upon Aboriginal society, and the resultant suppression of Aboriginal culture and values. As a result, it is not possible to consider the care of Aboriginal children unable to remain with their parents without also having regard to the socio-cultural context in which Aboriginal people are located, the manner in which sociocultural relations are structured in Aboriginal society and between Aboriginal and non-Aboriginal societies.

Cunneen (1997) argues that the human rights of Aboriginal young people and their families are being abused through a series of failures: the failure to reform juvenile justice law and practice; the failure to remedy the social justice issues facing Aboriginal youth; and the failure to respect the right of self-determination of Aboriginal peoples. He argues that the law and legal processes are not neutral, but harbor racist views, and criminalize and incarcerate Aboriginal young people disproportionately. $\mathrm{He}$ quotes figures from a police custody survey undertaken in 1995 that suggested that $40 \%$ of all young people in custody were Aboriginal, despite the fact that they constituted only $2.6 \%$ of the national youth population. The rate of custody per 100,000 Aboriginal young people was 1,333 compared with a rate of 52 for non-Aboriginal people, an over-representation factor of 26. It is therefore not unrealistic, given the history of the stolen generations, for Aboriginal people to see this as a continuance of the practice of forced separation of Aboriginal and Torres Straight Islander children and young people from their families.

Focusing attention on the Tasmanian Children, Young Persons and their Families Act 1997, Mansell (2001) points to the act's token recognition of Aboriginal involvement in decision making. Similarly, the New South Wales Children and Young Persons (Care and Protection) Act 1998, while promoting Aboriginal involvement in decision making, requires Aboriginal people to embrace the nuclear family as it does not provide for any other family models of decision making. In comparison, the United States Indian Child Welfare Act of 1978 ensures that all American Indian children, even those unable to remain with their parents, remain inside American Indian communities. In Australia, there is no guarantee that an Aboriginal child entering care will remain in an Aboriginal community nor is there any legislative requirement for either the court or the state department to involve the Aboriginal community in family group conferences about child placements.

Clearly then, there are legislative barriers to self-determination as well as entrenched practices that marginalize Aboriginal people, not only in child welfare and juvenile justice. These institutional barriers need to be challenged if effect is to be given to self-determining policies like the ACPP. The separation of Aboriginal children from their families through the child protection and the juvenile justice systems are "band-aid solutions" that avoid larger systemic issues.

\section{The Applicability of Research for Aboriginal Out-of-Home Care}

While research on non-Aboriginal out-of-home care has much to offer Aboriginal out-of-home care practice, caution must be exercised to ensure the cultural appropriateness of empirical findings. To do otherwise, to simply apply research uncritically, is to risk engaging in oppressive, unjust, and culturally inappropriate practices. Groza et al. (2003) provide an example to illustrate the difficulties of applying empirical research findings in practice in relation to sibling placements. They draw attention to the importance of sibling relationships and close sibling ties for children from dysfunctional families. They argue that since close sibling relationships often develop in problem families, separating siblings increases the trauma and loss associated with removal. However, policy does not seem to be following research data in this respect.

In 2001, the New South Wales government put through amendments to the Children and Young Persons (Care and Protection) Act 1998 to facilitate the early permanent placement of children who have recently come into care (Lo Po', 2001). Similar trends are evident in the U.S. and the U.K. where "the government has attempted to relocate child adoption at the centre of practice" (Garrett, 2003). Moves to facilitate permanency planning can reduce the chances of siblings not placed together ever being reunited and simultaneously reduce the likelihood of parents being reunited with their children. Such actions can also limit the chances of siblings separated in temporary care from ever being reunited with one another in foster care. Thus permanency planning or the emphasis at the policy level on successful closure needs to be seen in light of research data on successful placements as well as the complex questions facing those involved in Aboriginal out-of-home care that are exacerbated by resource constraints. For example, Aboriginal child 
placements often involve the placement of siblings. While research data shows that placing siblings together results in greater placement stability (Groza et al., 2003), locating and supporting such placements is extremely difficult and requires a great deal more effort, time, and support than a single child placement, and policies emphasizing speedy resolution only intensify the difficulties involved.

Another area where research data is difficult to apply in light of similar issues is in relation to ongoing contact between children and their families while they are in longterm care (Mapp, 2002).

The empirical child development literature stresses that identity development is strongly linked to children's birth families and draws attention to the importance of children knowing "where they come from." This theory is borne out by the fact that once children outgrow the out-of-home care system they often return to a family member (Mapp, 2002). Also related is the increasing research on the trau-
It is not enough to provide Aboriginal

organisations with additional funding to care

for all Aboriginal children in care. At the

moment they simply do not have the capacity

to respond. and that only minimal contact should be maintained as determined by the courts, unless there is expert evidence to the contrary. Very young children, especially, need to develop critical attachments to their caregivers. For older children, Tregeagle and Staff suggest that visits should be kept to a minimum as dictated by the child's needs, views, and life experience.

Most of the research into foster care and adoption is, however, based on non-Aboriginal values and theories. How, then, do findings such as these apply to Aboriginal children? There is no tradition of foster care in Aboriginal society. Rather, care is provided through the systems of kinship that exist in and constitute the community. In Aboriginal culture, the system of relationships in which the child is imbedded is as significant as the provision of care. Thus the idea of indigenous kinship care has developed in response to a social need constructed in non-Aboriginal culture with safeguards such as matic effects of adoption involving no parental contact (Verrier, 1993; 2003). Further, research suggests that the relationship with the birth family can help give children strength to endure the trauma of being in care and helps with their adjustment while in care (Ainsworth \& Maluccio, 2002; Mapp, 2002). While caseworkers need to continually assess family contacts to ensure that they are productive and in the best interests of the child, research data nevertheless emphasises the importance of ongoing contact between children in care and their biological families.

However, it seems that practice experience suggests that the issue of family contact is not that clear-cut. For example, Sue Tregeagle and Barnardos Staff (2003) found that in some cases high-level contact with birth families was detrimental to children placed in permanent foster care. While recognising the importance of family contact, Tregeagle and Staff question its benefits for all children in permanent care arguing that children may face split loyalties between caregivers and family members; caregivers may experience problems with the child after family visits; caregivers may not want to form too close a relationship for fear that the child will be restored to their birth families; or caregivers may be fearful of threats of violence, real or otherwise, from parents. Tregeagle and Staff go so far as to say that in the best interests of the child in permanent care one should seek to promote the child's attachment to the new family the ACPP to ensure culturally appropriate practice. Clearly, further research is needed in relation to the indigenous experience of foster care practice.

\section{Facilitating Culturally Appropriate Care}

From an Aboriginal perspective, the need to maintain the linkages between the ACPP, indigenous kinship care, and Aboriginal self-determination is strong and necessary if Aboriginal children are to be provided with culturally appropriate care. However, as we have seen, achieving such an outcome is not without its problems, and cultural tensions remain. What is the relationship-the similarities and differences-between Aboriginal and non-Aboriginal values and assumptions about child care and family welfare? Are the problems structural-do they arise from the marginalisation of Aboriginal communities? Are Aboriginal child welfare service providers being deliberately excluded from general decision making regarding Aboriginal child welfare? Does the solution lie in self-management-in transferring power, statutory responsibility, decision making, and service delivery from the state to Aboriginal communities? Would community-based Aboriginal services be more effective? What is the way forward?

Realistically there are not enough trained Aboriginal caseworkers available to enable the establishment of self-managed 
services. How might we respond to this? One option is for the government, in consultation with training institutions and Aboriginal communities, to develop and fund Aboriginal child welfare training programs for Aboriginal workers. This would be achievable if the government were to adopt a different approach to the funding of services. Instead of providing agencies with periodic lump-sum grants for salaries and administration, funding for casework salaries and services could be calculated separately. The funding of identified casework positions could then be supplemented to enable and require the participation of caseworkers in the requisite training.

In addition to the participation of Aboriginal people in the design and development of training programs, culturally appropriate practice models-particularly in regard to intake, assessment, and intervention—could be developed and implemented. Most importantly, Aboriginal self-determination requires considerable input and support from government in terms of resources and infrastructure development. While in the short term this will be a costly exercise, in the long term it should result in savings to government as Aboriginal communities develop their capacity to develop these essential culturally appropriate services.

\section{Conclusion}

There are no easy or short-term solutions to operationalising the ACPP. It is not enough to provide Aboriginal organisations with additional funding to care for all Aboriginal children in care. At the moment they simply do not have the capacity to respond. As well as increasing funding, authorities need to take a long-term incremental view to develop capacity within Aboriginal society to care for their children involving action on a wide range of fronts. However, the goals are clear:

- All Aboriginal children requiring out-of-home care placements should be placed through Aboriginal out-of-home care agencies.

- Caregiver assessment standards and training programs that reflect culture, kin, and community-based placement practices are required.

- The importance of community in the cultural identity of Aboriginal people must be recognized. It is this community-based view that makes the highly individualised models of service-rendering culturally inappropriate.

The need to restructure Aboriginal services is supported by research indicating that Aboriginal children prefer to have an Aboriginal caseworker available to them while in care (Community Service Commission, 2000). To this might be added, "... who is employed by an Aboriginal agency and who can place them with an Aboriginal caregiver with whom they have a significant relationship."
Clearly, much needs to be done to ensure that we are keeping Aboriginal children home within their culture and with their families and communities. While this article has focused particularly on foster care (or out-of-home care in Australia), there is also the other end of the service continuum that is needed to fulfill the Aboriginal Child Placement Principle. Early intervention and prevention is needed to address the reasons for the over-representation of Aboriginal children in care, and a well-resourced service infrastructure must be built within Aboriginal communities to provide the support and intervention needed for keeping them home.

\section{References}

Ah Kee, M., \& Tilbury, C. (1999). The Aboriginal and Torres Strait Islander Child Placement Principle is about self determination. Children Australia, 24(3), 4-8.

Ainsworth, F., \& Maluccio, A. (2002). Siblings in out-of-home care: Time to rethink? Children Australia, 27(2), 4-8.

American Bar Association. (1999). Guidelines to follow when children are placed in "kinship care." Retrieved on May 13, 2005 from the American Bar Association Web site: http://www.abanet.org/child/kinship.html

Australian Institute of Health and Welfare. (2005). Child protection Australia 2003-04. Canberra: Author.

Behrendt, L. (2003). Achieving social justice: Indigenous rights and Australia's future. Australia: Federation Press.

Boots, S., \& Geen, R. (1999). Family care or foster care? How state policies affect kinship caregivers. Washington, DC: The Urban Institute.

Child Welfare League of America. (2001). Standards of excellence for kinship care services. Washington, DC: CWLA Press.

Child Welfare League of America. (2003). A tradition of caring: Information, resources, and support for kinship families (assessment guide). Washington, DC: CWLA Press.

Chipman, R., Wells, S. J., \& Johnson, A. (2002). The meaning of quality in kinship foster care: Caregiver, child, and worker perspectives. Families in Society, 83, 508-520.

Chisholm, R. (1988). Towards an Aboriginal child placement principle: A view from New South Wales. In B. Morse \& Woodman, G. (Eds.). Indigenous law and the state. Netherlands: Fovis.

Community Service Commission. (2000). Voices of children and young people in foster care: Report from a consultation with children and young people in foster care in New South Wales. Sydney: Author. Retrieved on September 18, 2006 from http://www.ombo.nsw.gov.au/publication/compltelistreport.html\#c hildren

Crengle, S. (1998, July). Ma Papatuanuku, ka Tipu nga Rakau. Proceedings of Te Ora Rangahau, Te Putahi-a-Toi, School of Maori Studies, Massey University, Palmerston North. (p. 193).

Cunneen, C. (1997, June). The new stolen generations. Paper presented at Australian Institute of Criminology conference. Adelaide: South Australia.

Ehrle, J., \& Geen, R. (2002). Kin and non-kin foster care: Findings from a national survey. Children and Youth Services Review, 24(1/2), 15-35.

First Nations Child and Family Services. (2003a). Child in care service standards. Ontario, Canada: Indian and Northern Affairs. Manuscript in preparation.

First Nations Child and Family Services. (2003b). Foster family care manual. Ontario, Canada: Indian and Northern Affairs. Manuscript in preparation.

Groza, V., Maschmeier, C., Jamison, C., \& Piccola, T. (2003). Siblings and out-of-home placement: Best practices. Families in Society: The Journal of Contemporary Human Services, 84(4), 480-490.

Human Rights and Equal Opportunity Commission. (1997). Bringing 
Them Home: Report of the National Inquiry into the Separation of Aboriginal and Torres Strait Islander Children from Their Families. Retrieved on May 15, 2005 from the Australian Legal Information Institute Web site:

http://www.austlii.edu.au/au/special/rsjproject/rsjlibrary/hreoc

Leos-Urbel, J., Bess, R., \& Geen, R. (2002). The evolution of Federal and State policies for assessing and supporting kinship caregivers. Children and Youth Services Review. 24(1/2), 37-52.

Lo Po', F. (2001). Second reading speech for the Children and Young Persons (Care and Protection) Amendment Permanency Planning Bill (No2) Hansard. (p. 15585). NSW Legislative Assembly.

Mansell, M. (2001, March). Early investment: Finding the legal foundation to support Aboriginal self determination in the care of our families in trouble. Paper presented at the Australian Institute of Criminology conference on Children, Young People and Their Communities. Launceston, Tasmania. Retrieved on May 15, 2005 from the Australian Institute of Criminology Web site: http://www.aic.gov.au/conferences/cypc

Mapp, S. (2002). A framework for family visiting for children in longterm foster care. Families in Society: The Journal of Contemporary Social Services, 83, 175-182.

McHugh, M. (2003). A further perspective on kinship care: Indigenous foster care. Developing Practice, 8, 14-24.

Ministry of Social Development (2006). Communities, Hapu, Iwi. Retrieved on September 18, 2006 from the Ministry of Social Development Web site: http://www.dsw.govt.nz/workareas/communities-hapu-iwi/

New South Wales Department of Community Services. (2006). Annual Report 2004/05. Retrieved on September 18, 2006 from the Department of Community Services Web site: http://www.community.nsw.gov.au/html/Annual_report05/DG_rev iew.htm

New South Wales Department of Community Services. (2004). DoCS data (September 2004-March 2006). Retrieved on September 18, 2006 from the Department of Community Services Web site: http://www.community.nsw.gov.au/documents/docs_data/quarterly sept04_mar06.pdf

O'Neill, C. (2002). Together or separate? Sibling placements: A review of the literature. Children Australia, 27(2), 9-16.

Stanley, J. (2003, May). Child sexual abuse in Indigenous communities. Paper presented at the Australian Institute of Criminology conference on Child Sexual Abuse, Adelaide, South Australia.

Sweeney, D. (1995). Aboriginal child welfare: Thanks for the apology, but what about real change? Aboriginal Law Bulletin. 3(76), 4-9.

Terling-Watt, T. (2001). Permanency in kinship care: An exploration of disruption rates and factors associated with placement disruption. Children and Youth Services Review, 23(2), 111-126.

Tregeagle, S., and Staff, B. (2003). Establishing permanency for children: The issues of contact between children in permanent foster care and their birth families. Developing Practice, 6, 57-65.

United States Department of Health and Human Services (2006). Program funding, grant programs Retrieved on September 18, 2006 from the Administration for Children and Families Web site: http://www.acf.hhs.gov/programs/ana

Verrier, N.N. (1993). The Primal Wound: Understanding the Adopted Child. Lafayette, CA: Verrier Publications.

Verrier, N.N. (2003). Coming Home to Self: The Adopted Child Grows Up. Lafayette, CA: Verrier Publications.

Bruce Valentine, $\mathrm{PhD}$, is lecturer in Social Work, School of Humanities and Social Sciences, Charles Sturt University, Australia. Mel Gray, $\mathrm{PhD}$, is professor, Department of Social Work, University of Newcastle, Australia. Correspondence regarding this article may be sent to the first author at bvalentine@csu.edu.au or the School of Humanities and Social Sciences, Charles Sturt University, Locked Bag 268, Wagga Wagga, NSW, Australia 2678.

Manuscript received: August 11, 2005

Revised: May 16, 2006

Accepted: May 18, 2006

\section{Endnotes}

1 In this article, foster care is understood to refer generally to the court-mandated care provided to a child unable to remain in the care of his or her family by an unrelated person and supervised by a recognized child welfare agency.

2 While this article refers to Aboriginal people in Australia, the comments are equally applicable to Torres Strait Islander peoples. Most Australian states refer to the Aboriginal and Torres Strait Islander Child Placement Principle.

3 As used in this article, indigenous kinship care is not limited to relationships based on blood or marriage. Within Aboriginal communities, kinship networks are constituted by a vast array of linkages based on relationships of blood, marriage, association, and spiritual significance. Importantly, a person has brothers, sisters, mother, fathers, uncles, and aunts that are additional to relationships by blood or marriage. Within Aboriginal cultures, the rights and duties associated with relationships of association and spirituality are as binding as those of blood and marriage. From an Aboriginal perspective, any one of these persons could be involved in the provision of "kinship care." 